\title{
The Prevalence and Patient's Quality of Life for Asthma in Taiwan
}

\author{
Yung-hsiang Ying1, Yung-ching Weng ${ }^{2}$ and Koyin Chang ${ }^{3 *}$ \\ ${ }^{1}$ National Taiwan Normal University, Taiwan \\ ${ }^{2}$ Ming Chuan University, Taiwan \\ ${ }^{3}$ Department of Healthcare Information and Management, Ming Chuan University, Taiwan
}

Submission: February 03, 2017; Published: March 23, 2017

*Corresponding author: Koyin Chang, Department of Healthcare Information and Management, Ming Chuan University, Taiwan,

Email: kychang@mail.mcu.edu.tw

\section{Abstract}

Asthma affects approximately $5 \%$ of the population in Taiwan. The increasing prevalence has caused concerns for both general public and healthcare professionals. This study aims to understand patients' quality of life in order to provide guidance for appropriate healthcare service as well as prevention. Face-to-face interview was conducted using Asthma Quality of Life Questionnaire (AQLQ) in a community hospital in northern Taiwan. A total of 106 questionnaires were collected. The results indicate that patients concern mostly about environmental stimuli which causes the greatest worries in the four functions of AQLQ. Middle aged patients have the worse quality of life than other age group counterparts. This is largely due to the emotional and physical stress as the result of the disease.

\section{Introduction}

Asthma is a common chronic airway disease characterized by partially or completely reversible airway obstruction known as asthma attacks. The most common symptoms are coughing, dyspnea, and chest tightness. The adverse outcomes associated with asthma could lead to inability to work, hospitalization, disability, and morbidity. The disease places a heavy burden on governments, health care systems, patients, and their families. Worldwide estimates of the prevalence of adult asthma vary widely, from $0.8 \%$ to $13.4 \%$ [1]. Ethnicity and demographic and environmental factors may contribute to these diverse variations. In Taiwan, the prevalence rate of Asthma is estimated to be $5.1 \%$ [2] for general population. The prevalence rate can be doubled for children. However, the severity of asthma increases after 18 years of age and the mortality is high in the elderly [3]. The health care costs for hospital outpatient visits, urgent visits and hospitalization in adults with asthma are above 2 times of those without asthma [4]. Though numerous studies have examined the epidemiology of asthma in Taiwan [5], studies of the patients' quality of life are scant.

Thus, this study investigates patients' health-related quality of life employing The Asthma Quality of Life Questionnaire (AQLQ) developed by Juniper et al. [6] to understand patients' suffering from the disease.

\section{Methods}

Face-to-face interviews were conducted in a northern Taiwan community hospital. The inclusion criteria are 1. presence of symptoms of airflow obstruction (cough, wheezing, dyspnea), 2. Airflow obstruction is at least partially reversible (demonstrated by spiromentry at any time - FEV1 increased by $>15 \%$ following $\beta$-agonist inhalation) or evidence of bronchial hyper responsiveness by metacholine challenge (demonstrated by $\mathrm{PC} 20<8 \mu \mathrm{g}$ ), 3. Age is 18 years or older. Patients' obstructions involving large airways (such as foreign body in trachea or bronchus, vocal cord dysfunction, vascular rings or laryngeal webs, laryngotracheomalacia, tracheal stenosis or bronchostenosis, enlarged lymph nodes or tumor) or small airways (such as viral bronchiolitis or obliterative bronchiolitis, cystic fibrosis, bronchopulmonary dysplasia) and other causes such as drug induced symptoms or aspiration from swallowing mechanism dysfunction are excluded from the study.

\section{AQLQ questionnaire}

There are 32 questions in the four domains (symptoms, activity limitation, emotional function and environmental stimuli) of AQLQ. The activity domain contains 5 'patientspecific' questions. This allows patients to select 5 activities in which they are most limited and these activities will be assessed 
at each follow-up. Patients are asked to think about how they have been during the previous two weeks and to respond to each of the 32 questions on a 7 -point scale $(7=$ not impaired at all, and 1 = severely impaired). The overall AQLQ score is the mean of all 32 responses and the individual domain scores are the means of the items in those domains. Thus, AQLQ has scores range 1-7, with higher scores indicating better quality of life.

The validity of AQLQ was established by comparison to conventional clinical asthma measures (symptoms, peak flow rates, medication use, $\mathrm{PFT}$, airway responsiveness, global rating of asthma), generic HRQL measures (Rand; SIP) [7] clinical sensibility of the measure [8]; symptoms \& clinical efficacy [9].

\section{Implementation}

The data collection period was from February 2013 to February 2014. All the patients were referred to the interviewers by their physicians from the pulmonary clinics at a local community hospital in Northern Taiwan. The physicians explained the study purpose to the patients before referring them to the interviewers. If the patients were not willing to accept the interview then the physician would respect their decision. This study was approved by the IRB board of the hospital. Written informed consent was obtained from all participants before conducting the interview. Patients who did not know their diagnosis were not referred to us by their physician and consequently were not recruited into this study interview.

To control the quality of the interviews, all research interviewers participated in a 2-3 $\mathrm{h}$ training program and received a detailed training document that delineated the study purpose, language to be used, interview procedure and coding book.

Since the physicians explained the study purpose to the patients before referring them to the interviewers, the response rate of the study was fairly high. Around 123 patients were invited to take part and 106 of them answered the questions. Written informed consent was obtained from all participants before conducting the interviews. Patients who did not know their diagnosis were not referred to us by their physicians and consequently were not recruited. Patients with very severe symptoms would go to medical center for treatment. Thus this study comprise the subject with not-so-severely ill asthma patients at the time of interview.

\section{Results}

\section{The Patients Background}

The average age $( \pm$ SD) of our subjects is $58.48( \pm 17.01)$ years old with the oldest patient 85 years old and the youngest one 19 years of age. About $72 \%$ of the subjects are diagnosed with asthma for less than 10 years and around 10\% are diagnosed with asthma from 10 to 20 years. $40.7 \%$ of the subjects are cigarette smokers, and $24 \%$ of them received only primary school education. $27 \%$ of the subjects reported to have severe disease condition, $24 \%$ reported to be moderate condition, and only $9 \%$ to be mild.

\section{Results of AQLQ}

Table 1: Results of Quality of Life by Functions.

\begin{tabular}{|c|c|c|c|c|c|}
\hline Variables (N) & Activity Limitation & Symptoms & Emotional Function & $\begin{array}{l}\text { Environmental } \\
\text { Stimuli }\end{array}$ & Overall Quality \\
\hline \multicolumn{6}{|l|}{ Gender } \\
\hline Male (57) & 5.34 & 5.26 & 5.54 & 5.41 & 21.55 \\
\hline Female (49) & 5.05 & 4.81 & 5.21 & 4.56 & 19.63 \\
\hline \multicolumn{6}{|l|}{ Age } \\
\hline $18-19(2)$ & 6.5 & 5.17 & 5.6 & 6.25 & 23.52 \\
\hline $20-29(7)$ & 5.13 & 5.08 & 6.07 & 4.08 & 20.37 \\
\hline $30-39(9)$ & $3.28^{* *}$ & $2.88^{* *}$ & $3.55^{* *}$ & $2.75^{*}$ & $12.45^{* * *}$ \\
\hline $40-49(13)$ & 5.57 & 4.39 & 5.1 & 4.63 & $19.68^{*}$ \\
\hline $50-59(18)$ & 5.24 & 4.98 & 5.15 & 5.34 & 20.71 \\
\hline $60+(57)$ & 5.4 & 5.57 & 5.74 & 5.35 & 22.06 \\
\hline \multicolumn{6}{|l|}{ Education } \\
\hline Illiterate (10) & 5.18 & 4.35 & 4.68 & 4.75 & $18.96^{* * *}$ \\
\hline Literate (8) & 5.78 & 6.27 & 6.4 & 5.94 & 24.38 \\
\hline Primary (25) & 5.29 & 5.34 & 5.48 & 4.88 & 20.99 \\
\hline Middlesch(24) & 5.15 & 5.16 & 5.36 & 5.34 & 21.02 \\
\hline High Sch (24) & 5.53 & 5.38 & 5.8 & 5.48 & 22.18 \\
\hline College+(15) & 4.5 & 3.87 & 4.71 & $3.54^{*}$ & $16.62^{* *}$ \\
\hline
\end{tabular}


International Journal of Pulmonary \& Respiratory Sciences

\begin{tabular}{|c|c|c|c|c|c|}
\hline Cigarette & & & & & \\
\hline Yes(42) & 5.25 & 5.04 & 5.4 & 5.24 & 20.92 \\
\hline No (64) & 5.22 & 5.1 & 5.42 & $4.83^{* *}$ & 20.58 \\
\hline \multicolumn{6}{|l|}{ Disease Years } \\
\hline$<11(76)$ & 5.43 & 5.2 & 5.53 & 5.28 & 21.45 \\
\hline $11-20(13)$ & 4.08 & 4.03 & 4.32 & $4^{*}$ & $16.43^{* *}$ \\
\hline $21-30(7)$ & 5.23 & 5.08 & 5.8 & 4.67 & 20.78 \\
\hline $31-40(7)$ & 5.28 & 5.48 & 5.35 & 4.13 & $20.23^{*}$ \\
\hline$>40(3)$ & 4.4 & 4.71 & 5.5 & 4.5 & 19.11 \\
\hline \multicolumn{6}{|l|}{ Severity } \\
\hline Mild(13) & 5.3 & 5.36 & 6.07 & 4.83 & $21.56^{*}$ \\
\hline Moderate(24) & 5.18 & 4.93 & 5.35 & 4.76 & 20.22 \\
\hline Server (29) & 5.32 & 5.36 & 5.43 & 5.59 & 21.7 \\
\hline
\end{tabular}

$\mathrm{N}$ : Number of subjects in the parentheses. Average quality of life in the range of 1-7 for each function. Higher values represent better quality of life. * ${ }^{* *}$, and ${ }^{* *}$ represent $10 \%, 5 \%$, and $1 \%$, respectively, statistical significance in ANOVA analysis.

The results of QOL (quality of life) scores and the ANOVA analysis across groups are reported in Table 1. Notably, the

Table 2: Summary of AQLQ Scores

\begin{tabular}{|c|c|c|c|c|}
\hline Questions in AQLQ* & Mean & S.E. & Order in Functions & Order in all Function \\
\hline Activity Limitation & 5.23 & & & \\
\hline 1.Strenuous activities & 5.04 & 1.68 & 6 & 18 \\
\hline 2.Moderate activities & 5.64 & 1.48 & 4 & 6 \\
\hline 3.Social activities & 6.36 & 1.03 & 1 & 1 \\
\hline 4.Work-related activities & 6.08 & 1.29 & 2 & 2 \\
\hline 5.Lack of a good night's Sleep & 5.80 & 1.63 & 3 & 3 \\
\hline 11.Avoid cigarette smoke & 4.30 & 2.39 & 9 & 30 \\
\hline 19.Avoid dust & 4.66 & 2.22 & 8 & 27 \\
\hline 25.Avoid weather/air pollution & 4.74 & 2.21 & 7 & 26 \\
\hline 28.Avoid strong smells & 4.28 & 2.35 & 10 & 31 \\
\hline $\begin{array}{l}\text { 32. General activity limitation as a result of your asthma in the } \\
\text { past two weeks }\end{array}$ & 5.40 & 1.73 & 5 & 9 \\
\hline Symptoms & 5.07 & & & \\
\hline 6. physical and emotional impairments & 4.66 & 1.77 & 11 & 27 \\
\hline 8. Feel short of breath as a result of your asthma & 5.52 & 1.54 & 2 & 7 \\
\hline 10. Experience a wheeze in your chest & 4.94 & 1.87 & 9 & 22 \\
\hline 12. Feel bothered by coughing & 4.64 & 1.72 & 12 & 29 \\
\hline 14. Chest tightness & 4.98 & 1.65 & 7 & 20 \\
\hline 16. Clear throat & 5.00 & 1.91 & 6 & 19 \\
\hline 18. Difficulty breathing out & 4.80 & 1.99 & 10 & 24 \\
\hline 20. Wake in the morning with symptoms & 5.72 & 1.69 & 1 & 4 \\
\hline 22. Feelchest tightness or chest heaviness & 5.22 & 1.79 & 4 & 13 \\
\hline 24. Woken at night by asthma & 5.38 & 1.82 & 3 & 10 \\
\hline $\begin{array}{l}\text { 29. Have difficulty getting a good night sleep as a result of your } \\
\text { asthma }\end{array}$ & 4.96 & 1.98 & 8 & 21 \\
\hline 30. Heavy breathing & 5.12 & 1.91 & 5 & 16 \\
\hline
\end{tabular}

age group of 30-39 and patients with disease year 11-20 have the lowest overall QOL. Cigarette smoking behavior does not affect patients' overall QOL. But patients with cigarette smoking behavior are lot more susceptible to environmental stimuli than non-cigarette smokers, reflected by low QOL smokers. 
International Journal of Pulmonary \& Respiratory Sciences

\begin{tabular}{|c|c|c|c|c|}
\hline Emotional function & 5.04 & & & \\
\hline 7. Feel concerned about having asthma & 5.38 & 1.99 & 3 & 11 \\
\hline 13. Feel frustrated as a result of your asthma & 5.42 & 1.77 & 2 & 8 \\
\hline 15. Concerned re-medications & 5.18 & 1.97 & 4 & 14 \\
\hline 21. Feel afraid of not having your asthma medication available & 5.70 & 1.81 & 1 & 5 \\
\hline $\begin{array}{l}\text { 31.Concerned about activity limitation as a result of your asthma } \\
\text { in the past two weeks }\end{array}$ & 3.20 & 1.05 & 5 & 32 \\
\hline 27. Afraid of getting out of breath & 5.38 & 1.89 & 3 & 11 \\
\hline Environmental stimuli & 4.99 & & & \\
\hline $\begin{array}{l}\begin{array}{l}\text { 9. Feel bothered by or have to avoid cigarette smoke in the } \\
\text { environment }\end{array} \\
\end{array}$ & 4.76 & 2.23 & 4 & 25 \\
\hline 17. Feel bothered by or have to avoid dust in the environment & 4.94 & 1.93 & 3 & 22 \\
\hline $\begin{array}{l}\text { 23. Feel bothered by or have to avoid going outside because of } \\
\text { weather or air pollution }\end{array}$ & 5.10 & 1.90 & 2 & 17 \\
\hline $\begin{array}{l}\text { 26. Feel bothered by or have to avoid going outside because of } \\
\text { strong smell }\end{array}$ & 5.18 & 2.07 & 1 & 14 \\
\hline
\end{tabular}

Table 2 presents the relative importance for different functions. Among the four functions, activity limitation received the highest average score while environmental stimuli received the lowest, indicating that environmental quality caused the greatest concern for the patients. Patients are concerned about cigarette smoke around them and would do their best to avoid it. Though the function of activity limitation received a high score

Table 3: Reliability test for internal consistency.

\begin{tabular}{|c|c|c|c|}
\hline & & Cronbach $\boldsymbol{\alpha}$ & Question no. \\
\hline \multirow{4}{*}{ Reliability by functions } & Activity Limitation & 0.8222 & $1,2,3,4,5,11,19,25,28,32$ \\
\cline { 2 - 4 } & Symptom & 0.9296 & $6,8,10,12,14,16,18,20,22,24,29,30$ \\
\cline { 2 - 4 } & Emotional Function & 0.8359 & $7,13,15,21,27,31$ \\
\cline { 2 - 4 } & Environmental Stimuli & 0.8433 & $9,17,23,26$ \\
\hline Total reliability & All 32 questions & 0.9536 & \\
\hline
\end{tabular}

Note: Cronbach Alpha $<0.35$ low reliability

$<0.7$ medium reliability

\section{$>0.7$ high reliability}

\section{Conclusion}

An increasing prevalence rate of asthma in Taiwan has drawn attention to general population as well as health authority. Patients' health-related quality of life is of concern for both patients' family and healthcare personnel for providing better services. The result of this study indicates that patients worry mostly about the environmental condition and stimuli such as cigarette smoke that may cause uncomfortableness both emotionally and physically. Patients in the middle age group has the lowest QOL compared to younger and order counterparts. This is probably because that the patients in this age group takes main responsibility in the family and hence are under great emotional stress about physical impairments. Activity limitation is of less concern among the four functions in the for patients' quality of life, the concern about the loss in activity due to asthma is substantial, which received the lowest score in the questionnaire.

\section{Reliability test}

Finally, the reliability test was performed by Cronbach's Alpha and the results exhibited high internal consistency as shown in Table 3.
AQLQ questionnaire. However, the worries and fear for further impairments are the major reason for low QOL. This research is done in a community hospital in norther Taiwan where not the patients with most severe conditions go. An overestimate of patients' QOL is possible. Nonetheless, this paper provides an overall understanding about how asthma patients might feel in Taiwan. A good measure of environmental avoidance should be propagandized in order to alleviate patients' suffering both emotionally and physically.

\section{References}

1. Anandan C, Nurmatov U, van Schayck OC, Sheikh A (2010) Is the prevalence of asthma declining? Systematic review of epidemiological studies. Allergy 65(2): 152-167.

2. Taiwan National Health Interview Survey, 2013.

3. Hsiao HJ, Wang LC, Yang YH, Lee JH, Yu HH, et al. (2013) A nationwide survey of the severity, comorbidity, and mortality of hospitalized patients with asthma in Taiwan. Pediatr Neonatol 54(4): 254-260.

4. Sun HL, Lue KH (2008) Health care utilization and costs of adult asthma in Taiwan. Allergy Asthma Proc 29(2): 177-181. 
5. Ma YC, Lin CC, Yang SY, Chen HJ, Li TC, et al. (2015) Time Trend Analysis of the Prevalence and Incidence of Diagnosed Asthma and Traditional Chinese Medicine Use among Adults in Taiwan from 2000 to 2011: A Population-Based Study. PLoS One 10(10): e0140318.

6. Juniper EF, Guyatt GH, Ferrie PJ, Griffith LE (1993) Measuring quality of life in asthma. Am Rev Respir Dis 147(4): 832-838.

7. Rowe BH, Oxman AD (1993) Performance of an asthma quality of life questionnaire in an outpatient setting. Am Rev Respir Dis 148(3): 675681
8. Rowe BH, Oxman AD (1993) An assessment of the sensibility of a quality of life instrument. Am J Emerg Med 11(4): 374-380.

9. Rutten-van Mölken MP1, Custers F, van Doorslaer EK, Jansen CC, Heurman L, et al. (1995) Comparison of performance of four instruments in evaluating the effects of salmeterol on asthma quality of life. Eur Respir J 8(6): 888-898.
This work is licensed under Creative Commons Attribution 4.0 Licens

DOI: 10.19080/IJOPRS.2017.01.555560
Your next submission with Juniper Publishers will reach you the below assets

- Quality Editorial service

- Swift Peer Review

- Reprints availability

- E-prints Service

- Manuscript Podcast for convenient understanding

- Global attainment for your research

- Manuscript accessibility in different formats (Pdf, E-pub, Full Text, Audio)

- Unceasing customer service

Track the below URL for one-step submission https://juniperpublishers.com/online-submission.php 